\title{
Digital Economy Barriers to Trade Regulation Status, Challenges, and China's Response
}

Ahmed Arafa Abdelrehim

Asif Khan ${ }^{2}$

Nishan-E-Hyder Soomro ${ }^{3 *}$

1,,,school of Law, Zheng:hou
University,China.
'Email: ahmedarafa66@@yhoo.com
'Email: drasifphdlaw@yahoo.com
'Email:nishanehydersoomro@gs.zzu.edu.cn

Licensed:

This work is licensed under a Creative Commons Attribution 4.0 License.

Keywords:

Digital barriers

Digital economy

data flow

Privacy data

Regional trade agreements.

Received: 2 February 2021 Revised: 5 March 2021 Accepted: 30 March 2021 Published: 22 April 2021 (* Corresponding Author)

\begin{abstract}
At present, the WTO's multilateral trading system faces the acute challenge of adapting to the digital and commercial economies' rapid evolution. The recent regional trade agreements embody the corresponding achievements of the Comprehensive and Progressive Agreement for Trans-Pacific Partnership (CPTPP), Economic Partnership Agreement (EPA), and the United States Mexico Canada Agreement (USMCA) in facilitating the free flow of data and regulating digital barriers to trade. The General Data Protection Regulation (GDPR) has also developed several new norms for promoting free data flow and protecting personal data privacy. The new regional trade agreements fulfil the digital trade threshold, prohibit delocalization by the data center and establish organized frameworks for cross-border data flow and personal privacy protection. In the negotiations on trade services agreements, China should focus on implementing a new management structure, speeding up domestic legislation and legislative reforms, and establishing a legal framework that promotes the free flow of data, fair competition, and personal information among corporations.
\end{abstract}

Funding: This study received no specific financial support.

Competing Interests: The authors declare that they have no competing interests.

\section{Introduction}

The digital economy, based on the internet and digital technology, has become a new economic development model after the agricultural, industrial, and information economy. The digital economy depends on the internet, big data, cloud computing, and artificial intelligence. The Digital era, such as artificial intelligence, is expanding around the world. It brings opportunities for development in all countries and brings new challenges to trade and rule-making among countries. As digital trade changes the traditional trading system in goods, services, and intellectual property rights, it also produces new types of digital trade barriers that differ from traditional tariff barriers and non-tariff barriers. Existing World Trade Organization (WTO) rules have been outdated in dealing with new types of digital trade barriers, and the Doha Round, which began in 2001, has stalled (Khan, Jillani, Abd Elrhim, \& Soomro, 2020). In this context, developed countries have led and entered into new regional trade agreements or regulations such as the Trans-Pacific Partnership Comprehensive Progress Agreement (CPTPP), the EU-Japan Economic Partnership Agreement (EPA), the US-Mexico Agreement (USMCA), and the General Data Protection Regulation (GDPR). Recently negotiated regional trade agreements promote cross-border data flows, protect privacy, and promote digital economic development. China should play a leading role in multilateral or regional negotiations to promote data flow and security, fair competition and privacy protection, and implement new legislation to promote domestic network security, fair competition, and privacy protection (Khan et al., 2020).

\section{Digital Trade Barriers and it is Impact on International Trade Law Framework 2.1. Digital Trade Barriers}

In the age of the digital economy, the digital economy needs to improve the free flow of data and information and the outcome of economic globalization and digital industrialization. However, information 
relating to public communications, transport, water, finance, public services, and open data and information flows can significantly affect national security due to the broad data needs for the digital economy and trade growth. Hacking can create significant threats to the protection of personal property and even national security. The State must regulate restrictions on the external access and data flow of connected networks to ensure the security of the national cyberspace, national economy, and people's livelihood infrastructure and public services and avoid the loss of national property caused by personal data leakage (Liu, 2018).

Many countries have adopted domestic legislation to provide regulatory measures such as data storage and data traffic restrictions. For example, Russian regulation includes the localization of electronic communications and social network data for its citizens, and laws can limit access to or even ban websites for corporate network authorities that do not enforce the regulation (Savelyev, 2016). In Australian laws, the information is relevant enough to be stored, held, managed, or processed (Webb, 2003). Data from the public sector, such as hospitals, schools, cannot be accessed from abroad in British Columbia and Nova Scotia, and Canada (Wong et al., 2018). The Government of Singapore has banned internet access to official computers since May 2017 (Li, Taeihagh, \& De Jong, 2018). Article 37 of China's Cyber Security Law also specifies: Personal information and important data collected and produced by critical information infrastructure operators in the activity of the People's Republic of China shall be stored in the territory and, where it is necessary to provide it abroad based on business needs, shall carry out a security assessment following the methods prescribed by the State Internet and the Cooperative Information Department (Shanxing \& Weiqi, 2017).

When many countries impose data flow restrictions or data flow restrictions measures, the data flow around the world does not lead to increased distress, a higher cost due to compliance, and an increase in operating and compliance for digital technology companies. According to the United States International Trade Commission (USITC) and the Global Economic Survey, 22 percent of digital technology firms, 24 percent of digital social enterprises, and 25 percent of wholesalers claim that foreign digital trade barriers are being removed; their earnings will increase by more than 15 percent (Lee-Makiyama, 2014). Data localization storage, data cross-border movement restrictions, data traffic restrictions, and open-source code and encrypted keys become new digital barriers to trade in the digital economy. Data localization storage is a national requirement for local control and regulation of data, including local storage and processing; the prohibition of forwarding, data localization measures will prevent digital technology companies from carrying out detailed work, or cannot be transmitted or stored information abroad, fundamentally limiting the development of digital trade. Restrictions on cross-border data flow lead enterprises to conduct trade without the basis of mutual agreement with the other party so that selected cooperative enterprises are often not the best choice to carry out such trade activities, contrary to the spirit of free trade. Open source and encrypted keys virtually require foreign investors to provide their commercial source code or encryption keys before entering their home markets as a prerequisite for foreign investors to enter the market. This requirement is likely to expose investors' trade secrets and put foreign investors at a competitive disadvantage.

\subsection{Current Multilateral Trade Agreement Framework for Digital Trade Barriers}

The WTO is a multilateral trade agreement framework covering trade in goods, services, and intellectual property rights reached at the end of the 20th century. Although digital trade has emerged during the eightyear Uruguay Round of negotiations, digital trade is not as important today. It does not show the many problems it faces today. The General Agreement on Trade in Services (GATS) and the Agreement on TradeRelated Intellectual Property Rights (TRIPs) under the WTO framework have been arranged for matters related to the digital economy. However, they are far from meeting the needs of the rapid development of the digital economy. In 1996, 29 member countries of the Singapore Council of Ministers signed the Ministerial Declaration on Trade in Information Technology Products. Its accompanying list of products is known as the Information Technology Products Agreement (ITA) (Mitchell \& Mishra, 2017). On 16 December 2015, the WTO extended its ITA product portfolio with the rapid development of digital technology and the expanding range of information technology products. The parties announced an agreement in Nairobi, Kenya. They released statements and declarations on increasing trade in information technology products. Member Parties undertake to introduce zero tariffs on information technology products included in the attached list of products through the ITA Agreement. Since 1998, the WTO has issued the Global E-Commerce Declaration (DGEC). Trade ministers acknowledge that global e-commerce is growing, creating new trade opportunities, and pledging to exempt electronic transmissions from tariffs temporarily (Gao, 2018). Since then, the WTO Ministerial Conference Declaration has continued the commitment to exempt electronic transmission from customs duties temporarily. However, the Doha Round, which had lasted more than a decade, had had little effect because of setbacks in multilateral trade negotiations and remained at the level of the earliest agreement on digital trade (Khan et al., 2020).

In this way, the establishment of WTO represents unprecedented progress in negotiating multilateral rules on trade in goods in the international community, which has formed more mature regulations on trade in goods. However, the WTO has only just launched to make multilateral rules on trade in services. In the more than 20 years since the establishment of the WTO, international trade in services has made rapid progress, with trade in services accounting for 20 percent of global trade in 2014 as measured by the traditional balance 
of trade, while trade in services accounted for about 50 percent of global trade by value-added norms. As the new digital economy industry is mainly indicated in trade in services, the international community's inadequate supply of rules on trade in services has restricted the development of trade in services. The multilateral trade rules in services under the GATS framework also appear to be outdated, manifested in the following three aspects (Mitchell \& Mishra, 2017).

Though the first GATS list four trade types in services and sets out the general and specific commitment obligations of member parties to the services, GATS has not foreseen and covered the new type emerging in the current digital trade and has never made adequate provisions for digital trade and access to new services for service providers of other member parties. Highlighted by the rapid growth of the digital economy, the incorporation of digital technology into end-product manufacturing is becoming increasingly popular, known as "services embedded in goods." It has become a new trade type in services, and GATS cannot cover this nondirect service value-added trade (Bombińska, 2019). The United States' efforts to influence the cross-border provision of "gaming services" (Trachtman, 2005) in China affect trading rights and distribution services for audiovisual entertainment publications ( $\mathrm{Wu}, 2009)$. The WTO Dispute Settlement Body intends to extend its member parties to new service products that have emerged from the earliest service obligations. However, this does not necessarily mean that GATS can naturally cover new service sectors that have not yet occurred, which have never been predicted. In the US case, the WTO Dispute Resolution Process has expanded its access to the offline gaming industry with legislation to influence cross-border gaming services. The obligations to cross-border online gaming firms in the US claim that the online gambling industry does not commit to market access. The dispute's emphasis is whether the access responsibilities of the "Recording Distribution Services" sub-sector of the "Audio-visual Services" sub-sectors of the China Accession Protocol include the online distribution of non-physical audiovisual goods. The WTO Dispute Settlement Body has declared that "audiovisual products" are not limited to tangible products but also intangible products and services (Wu, 2009).

Second, under the current case, a significant digital trade feature is that many digital products (books, music, movies, games, etc.) are traded and transmitted online through the internet. The main problem to trade is no longer tariffs but has evolved into a wide range of "post-border measures." Including regulation of crossborder data flows and network access (Kahn \& Wu, 2020). The GATS Annex on Telecommunication Services provides that the Member States ensure that other member service providers can access and use their public telecommunications transmission networks. Following the principles of non-discrimination, to transmit information within their territory or across borders. It promised on the commitment obligation already made in the Member States' schedule. Member Parties reserve the right to take the necessary measures to ensure the security and privacy of information. Besides, GATS Section 14 leaves member parties with broader exemption grounds based on general and security exceptions. Member parties may maintain public morals, life, and health, protect personal information, or impose restrictions that are inconsistent with their commitment obligations on the grounds of national security interests. At the same time, GATS and its annexes address to some extent the non-discriminatory treatment of cross-border trade in services and the prevention of the use of monopoly telecommunications enterprises to limit competition. It is far from sufficient to address new trade types in services and data movement restrictions in the digital economy context. In the Case of US Measures to Influence Cross-Border Gaming Services, although the WTO Dispute Settlement framework declared that the US restrictions on market access for Antigua's online gaming industry violated GATS, the US lost the case. It tried to circumvent enforcement awards. The WTO Dispute Settlement framework conducted several arbitrations on enforcement issues, finally authorizing Antigua to take disciplinary measures against the United States. Nevertheless, in Antigua's economy, the impact of such retaliation on the United States is almost insignificant (Kahn \& Wu, 2020).

Third, though The ITA Agreement established after the WTO's establishment, which is devoted to exempting electronic information products from customs duties and declared through the Global E-Commerce Declaration (DGEC), is temporarily exempt from tariffs electronic transmissions. However, both agreements are practically imperfect. First, the ITA Agreement is a bilateral trade agreement that applies only to some of the members that have signed it. Many WTO members who are not members of the agreement are not bound by it. Second, the ITA agreement remains limited to electronic information products, i.e., zero tariffs on electronic information products with clear material carriers, which do not apply to new types of trade-in virtual digital products through network transmission. Third, DGEC is currently limited to countries' temporary exemption from electronic transmission tariffs in e-commerce activities. It does not address the legal character of digital products transmitted electronically and the possible restrictions on countries' data transmission. What is more, the DGEC itself is only a declaration of the WTO Council, does not have the mandatory binding force of multilateral trade agreements, and is a quick decision that does not solve many of the problems related to electronic data transmission (Filonova, Polyakova, Neverov, \& Mayboroda, 2020).

\section{Digital Trade Barriers Provisions in New Regional Trade Agreements}

Because the WTO is not adequate to resolve the emerging digital trade barriers, developing countries have launched regional trade agreements involving new forms of trade in services. After the US withdrew 
from the TPP, the Japan-led Comprehensive Progress Agreement on the Trans-Pacific Partnership (CPTTP), the Economic Partnership Agreement (EPA) signed by the European Union and Japan, the U.S.-led revision of the U.S.-Mexico Agreement (USMCA) at the end of 2018, and the General Data Protection Regulation (GDPR) introduced by the European Union all provide for digital flows of new forms of trade in services and e-commerce. Specifically, the new free trade agreement, represented by CPTPP, EPA, and USMCA, incorporates many "post-border measures" into the agreement negotiations and requires member states to implement it as an essential outcome for the agreement. These new free trade agreements are a distinctive feature of the latest free trade agreements, which progressively and significantly influence the individual member states' systems and policies and dramatically increase the global market strength. The response to digital trade barriers in new regional trade agreements focuses mainly on trade in services and the free movement of data below (Li et al., 2018).

\subsection{New Provisions for Digital Trade-in Service}

In exploring new rules for trade in services, it is essential not to lose sight of the "service trade agreement" initiated under the former Obama administration TISA negotiations (Agreement, 2019). The TISA negotiations have virtually stalled since the Trump administration took office. However, the developing ideas it represents have severely impacted the subsequent negotiations on significant regional trade agreements, the core of which reflected in the USMCA, CPTPP, and new U.S.-led agreements. The rules of international trade in services in the new regional trade agreements are mainly represented in three areas: the model adopted by the commitment to open services, the opening up of the two crucial service sectors of finance and telecommunications, policy transparency, and regulatory measures.

First, by adopting a commitment model, a mixed model of festive listings for the service sector has been experienced in forming new rules for the trade-in services through the GATS positive inventory model. In the TISA negotiations, the national treatment lists eventually shifted to the pessimistic inventory system for the services trade and investment sectors CPTPP, EPA, USMCA, and the pre-access national treatment for the services sector. It should be noted that subsequent adopters, such as the USMCA CPTPP, have adopted the parallel implementation of the "frozen clause" and "ratchet clause" rules based on the pessimistic list created during the TISA negotiations. The frozen provision allows the parties to make a promise, from the moment that the agreement comes into effect, not to introduce new or restrictive trade and investment restrictions. The ratchet clause provides for the liberalization of trade and investment by Parties in an active, unilateral, and autonomous manner. Once committed, it will be incorporated into and permanently bound by the next round of negotiations.

Second, CPTPP, USMCA, separate chapters "Financial Services" and "Telecom Services," in the financial and telecommunications sector and the EPA, while not establishing separate chapters, also include sub-items in the text agreement. In the Financial Services section, all three provide national treatment, MFN treatment, market access, etc. The USMCA also includes obligations to liberalize the market for financial services and provide US financial institutions, investors, and cross-border financial services with a level playing field, representing the highest openness in the current trade in financial services. Unlike the transborder data transfers regulations in the chapter "Digital Trade," which grants Parties the right to adopt restrictive measures for specific purposes, the USMCA has added the free transfer clause for cross-border financial information. Simultaneously, the USMCA prohibits the localization of financial data storage, but service providers should ensure that regulators have timely and adequate access to appropriate information. In the Telecommunications Services section, CPTPP, USMC regulates and commits to telecommunications network access and use. It requires the Parties to ensure that, on the other hand, any endeavors have access to the transmission of information within and across obligations through any public telecommunications network or service (Gantz, 2018).

Thirdly, concerning transparency and regulatory policy provisions in trade in services, new trade agreements clearly define member parties' obligation to increase transparency and harmonize regulations to reduce services' costs through the corresponding rules. In terms of regulatory consistency, the CPTPP advocates the adoption of internationally recognized rules and regulations in financial services norms, the implementation and application of international rules against tax evasion and avoidance to achieve balance and coordination under the financial regulatory systems of the international community and promote further liberalization of financial markets. The USMCA further optimizes precautionary exceptions to cross-border trade in financial services, clarifies the exceptional characteristics of its regulation, and extends the spectrum of prudential exceptions for security, including areas that cannot be included in a 'no' model for prudential exception safety. The EPA enhances regulatory cooperation between Japan and the European Union to reduce unnecessary instruction and business regulations in Japan and the European Union.

\subsection{Rules on Digital Trade}

The digital trade rules of the current regional trade agreements can be divided narrowly into "Accessible" represented by the United States and "Conservatives" represented by the European Union. The two sections focus on prohibiting data enforcement's localization, prohibiting the mandatory disclosure of source code, and recognizing electronic signatures' legal impact. However, the cross-border flow of data and personal 
information and privacy protection rules is entirely different, reflecting different regulatory paths and strategic endorsements.

\section{a. Rules for Cross-Border Data Flows, Such as CPTPP and USMCA}

The TPP (now the CPTPP) and the USMCA agreement represent its digital trade rules based on three main aspects to focus on the actual US interests. Promoting the flow of data on which trade in digital services depends, protecting intellectual property rights in digital products, and improving countries' market access to the digital industry, high openness, and stringent protection standards.

CPTPP continues the original TPP "e-commerce" section of the regulation of digital trade, including the electronic transmission exemption from customs duties, non-discriminatory treatment of electronic products, domestic electronic transaction regulatory framework, recognition of electronic authentication and electronic signature legitimacy, online consumer protection, personal information protection, cross-border free transfer of business information, the prohibition of mandatory data localization, excess e-commerce information processing and prohibition of disclosure of source code and other provisions.

In the CPTPP, a new "digital trade" chapter and new regulations that form the latest and highest norms for digital trading in today's international trade agreements are added by USMCA and offer a strong basis to expand trade and investments in innovative digital goods and services with a competitive advantage in the US. In addition to consistent with the CPTPP in terms of allowing cross-border movement of data, nonmandatory localization of data storage, non-mandatory disclosure of source code and algorithms, prohibition of tariffs or other discriminatory measures on electronic transmission products, ensuring unrestricted use of electronic authentication or electronic signatures by suppliers, and ensuring enforceable consumer protection, The USMCA has immensely struggled to ensure the free cross-border movement of data: on the one hand, the USMCA has removed the "exception clauses" of data flow rules such as "free flow of cross-border data" and "non-mandatory localization of data storage" as set out in TPP, i.e. it is not enough to prevent the "free movement of data across borders" as defined by the USMCA, indicating that the United States wants to establish its world dominance and economic dominance through its own strong rules. The USMCA has also added additional content to promote cooperation to combat cybersecurity challenges and promote industry best practices to secure networks and services, promote the opening of government public data, and limit the civil liability of Internet platforms for third-party content hosted or processed by Internet service providers, in an effort to facilitate broader cross-border data flows (Gantz, 2018).

\section{b. Rules for Data Protection, such as EPA and GDPR}

In direct contrast to the United States, with Japan's European Union, the European Union is more cautious in liberalizing the cross-border flow of personal data. The digital trade rules represented by the EPA and the EU GDPR showing strict protection of data. Europe has implemented strong protection legislation on the rights of personal information, privacy, and other human rights derivative rights in long-term historical development. Secondly, based on the actual circumstance of the lack of significant Internet firms in the European Union, to compensate for the digital sector's economic deficit, to cultivate and establish local Internet companies as soon as possible. To resist the digital market penetration of the European Union by Internet firms in the United States and medium-sized countries, it hopes to focus on strict regulations on the cross-border flow of data.

In effect since 25 May 2018, the General Data Protection Regulation (GDPR) represents the strategic priorities and policy structures of the EU in the field of global digital trade. The GDPR provides for data rights, transfer of personal data to third countries or international organizations, and legislation to be developed balancing the protection of personal information of people and encouraging and promoting the data economy's growth (Dai, 2020). GDPR data transfer regulations are divided into general principles and four particular rules on data transfer. General principles define that personal data may only be transferred to third countries or international organizations if it complies with GDPR. Specific data transfer rules provide for four modes of transmission "based on a decision on authority" (article 45), "providing appropriate protections" (article 46), "binding corporate rules" (article 47), and "exceptions in exceptional circumstances" (article 49). The EU has specific rules for transferring data to all dimensions, aiming to ensure the free flow of personal data across borders, from the regional level to the international level of business, at an exceptional individual stage. At the same time, the application of the rules of "fullness determination" and "appropriate protections" to the cross-border transfer of massive and regular data, and the granting of the conditions of conformity to the rules to the EU authorities, reflect the EU's attempt to improve its control over personal data in the world's digital trade through rule-building.

In the 'E-Commerce' chapter of the EPA, Japan, and the European Union have agreed only to prohibit the compulsory transfer or procurement of the source code, exclude the transmission of electronic information from customs duties and accept the legal validity of the provisions on electronic authentication by electronic signature. It requires all parties to take or sustain steps to give consumers the right to refuse to receive or reduce junk e-commerce information, a common rule of the CPTPP and USMCA agreements. Besides, the EU has not made concessions on data localization and the free cross-border movement of data. The Japan-EU EPA's e-commerce norms do not exceed the CPTPP and USMCA members' commitment. However, on 5 
September 2018, the European Commission (EC) initiated a review process for Japan's "stability decision" in Brussels and confirmed the application of the "fullness decision" to Japan on 23 January 2019 (EU, 2019). As a result, the EPA, which entered into force on 1 February 2019, was the first EU agreement with a third country to be negotiated based on mutual recognition that appropriate security provisions have been fulfilled. The parties agreed to treat each other's data protection systems as "equally valid" and allow the free transfer of data between the two parties, so-called "establishing a secure data circulation zone," as a valuable complement to the EPA agreement the cross-border transfer of data.

\section{The Regulation of Digital Trade Barriers and China's Response 4.1. Reforming of $G A T S$}

While the rapid growth of the digital economy has brought a new round of development opportunities worldwide, digital trade has also generated several challenges that have not been addressed under the existing multilateral system. In the context of the current international trade instability, regional trade agreements such as the CPTPP, EPA, and USMCA create a rule structure for digital trade responsive to digital trade development. GDRP, on the other hand, has created a new kind of data flow rules that address the free flow of data with privacy protection rules. As a beneficiary of the multilateral trading system, China should use the WTO's multilateral negotiating system to actively guide the establishment of digital trade barriers of common concern to all countries and negotiate new trade rules adapted to the digital economy's development.

At present, most countries, including China and the European Union, have proposed reforms WTO proposal, in which the creation of multilateral digital trade regulations has become a compelling comfort (Petri, Plummer, \& Zhai, 2012). In order to resolve the current lack of rules on digital trade in the multilateral trading system, solutions should consist of two sections, one to ensure that digital barriers directly affecting foreign trade in goods and services are resolved and the other to address how governments can regulate crossborder data flows more generally (Meltzer, 2015). The absence of requirements relating to digital trade barriers is one of WTO multilateral agreements' problems. The limited scope of implementation of the current regional trade agreement is a weakness.

The key to resolving the issue of international digital trade rules is, therefore, to absorb the digital trade rules that have been established in significant regional trade agreements, to use and improve the principles of trade in services, market access, and national treatment already established in the GATS agreements, to play a part in the WTO multilateral trade dispute settlement mechanism and to solve the problem. The existing General Agreement on Trade in Services (GATS) applies only to sectors where member parties have made uncertain liberalization commitments. It applies to the new type of online services trade, where the mostfavored-nation and national treatment principles under the General Agreement on Tariffs and Trade (GATT) apply to tariff reduction obligations for all goods. There is a more advanced system of rules for regulating online trade. GATS mode 1 (cross-border provision) applies to trade patterns where consumers and service providers do not cross borders. The services themselves are transferred to the consumer's location across borders through the Internet or telecommunications networks. The explanation of the GATS application for online delivery services is a more feasible approach to the difficulties confronted by the current online crossborder trade model for digital goods. In this connection, CPTTP provides for no tariffs on electronic transmissions, including content transmitted electronically. It is assessed not to tax digital products that are highly advanced and meet digital trade development. As for the export of services in domestic intermediate service inputs in a country's export commodities, the so-called "services embedded in goods." Although the high added value of scientific and technological products could still be incorporated into the goods, the GATT principle of more acute national treatment and MFN treatment could be applied (Green, 2020).

In accordance with the needs of digital economic growth, a multilateral framework must also give the Member States adequate scope to regulate cross-border data flows while facilitating the removal of digital trade barriers. Indeed, the general derogation from Article 14 and the derogation from Article 14(2) of the current GATS reserved ample immunity for the Member States to maintain measures inconsistent with their specific and universal obligations. WTO members may enforce regulatory measures, such as restrictions on cross-border data flow and personal information protection, subject to GATS general and security exceptions. Accordingly, Article 37 of China's Cyber Security Law stipulates that operators of critical information infrastructure shall store personal information and important data collected and generated in China's domestic operations, which may be exempted under GATS's security exceptions.

ii. Promote the implementation of a constructive framework for inventory management in the recent service trade negotiations.

The rapid growth of the digital economy in terms of international trade is also reflected in the impact on the GATS members' challenge of establishing a "productive inventory" framework for practical system obligations. Under the current model, WTO participants expect restricted market access and national care responsibilities only in the GATS table of reduction obligations domains. On the other hand, in areas such as digital economic trade, which was never envisaged during the GATS talks, members are essentially granted the freedom to take necessary restrictive steps. In recent trade agreements, such as CPTPP and the USMCA, more advanced " productive list" frameworks have further liberalized trade and investment. The efficient 
inventory system will automatically adapt to the requirements for further liberalization of national laws and regulations for ever-changing digital trade. It will facilitate more substantial liberalization of trade and investment. A constructive list model would freeze Member States' obligations to reduce their obligations at the amount initially promised, and more expensive negotiations would be needed for further liberalization. Thus, in recent trade negotiations on services, introducing a productive inventory system enables the parties to exclude themselves from some liberalization commitments in the related national economy and people's livelihoods and social infrastructure services and include most non-Member States the digital industrial market. Member parties enforce data flow regulations in a pessimistic inventory model primarily on legitimate grounds, such as national security, public ethics, and preventing privacy data breaches by their people. The general exception to GATS Section 14 states that a member implements laws or measures based on privacy and security. Security exception to section 14 (2) requires the member to provide information contrary to fundamental security interests if disclosed.

Consequently, the general exemption from Article 14 of the GATS and the protection exemption leaves space for the Member States to perform digital trade cyber-national security assessments, which can affect public safety. Implementing the new 'pessimistic list' system trade negotiation service does not preclude the enforcement of cross-border based data restrictions by Member Parties. However, they ideally introduce general exceptions and security exceptions into the GATS, prohibiting members from enforcing discriminatory or unjust discrimination or veiled restrictions. The International Investment Law adopted by China in 2018 clearly defines "the state's national treatment before the International investment is subject to a pessimistic list management system." It establishes the legal basis for China to accept this new type of trade and investment model. Next, China should promote the inclusion of the "pre-access national treatment plus pessimistic list management system" system in trade negotiations in services. The scope and level of growth of China's current digital economy make it not only eligible to embrace the "pre-entry national treatment plus pessimistic list" system but does not preclude China from enforcing the required safety regulations by incorporating this new regulatory concept.

iii. Establishing domestic laws to facilitate digital trade and data regulation coordination.

Digital trading provides all countries growth opportunities and takes all countries' international regulatory issues. The challenges raised by digital trade are concentrated in three areas: the development of digital trade needs the free flow of data between countries at the national level, the free flow of data without restrictions poses significant challenges to national security, and the excessive focus on strict national security regulation impedes the development of digital trade; However, how to balance development in digital technology, data-free flow efficiency, and fair competition is an outstanding problem of competition regulation, personal level, since data contains ordinary people's privacy information, data-free flow can give up serious problems of personal data leakage and privacy protection, but the protection of non-differentiated personal information can give up severe problems of data leakage and privacy protection (Filonova et al., 2020).

\section{a. Coordination of Data Monopoly and Fair Competition}

Coordination between the monopoly of data and fair competition is a significant challenge to different countries' anti-monopoly legal structures. In an industrial economy era, the traditional anti-monopoly legislation was established, which primarily resolves market failure caused by industrial firms engaged in collusion, corruption, and economic concentration. The traditional anti-monopoly law's research approach is challenging to address current network-based data rivalry issues such as algorithm collusion, algorithmic discrimination, data set, technological innovation, etc. As the representative of developed countries, Germany has adopted new rules in the ninth reform of the Anti-Restrictive Competition Law, a multilateral market or network consequence (Kerber \& Zolna, 2020). China's newly amended Anti-Unfair Competition Law in 2017 ads a so-called "Internet specialty" on the regulation of unfair competition on the internet. The draft Antimonopoly Law of the People's Republic of China (Amendment Draft), published in October 2019 by the State Administration for Market Regulation and Administration, also introduces a new form of recognition factor relating to the dominant market position of Internet sector operators. The 'Internet Special Article' and the draft Antimonopoly Law emphasize that competition laws do not take adequate account of technological progress and economic performance arising from the free flow of data and do not provide a mechanism to promote the free flow of information. The Fair Stability of Competition, currently the competition policy law of China, needs to pay careful attention to the significant issues.

\section{b. Coordination of Data Flow and Privacy Protection}

Current Chinese laws still neglect proper consideration of data security and data use, privacy and fair use of personal information, and the empowerment of personal data protection is also incomplete. For instance, the Cyber Protection Act forbids the external transfer of personal data from a sensitive information infrastructure. However, restrictions on the flow of unclassified personal data may inhibit the growth of standard data transmission and digital trading. Article 43 of the Data Security Legislation establishes the right to remove and update personal information. The E-Commerce Law allows e-commerce operators to comply with the appropriate system according to the user's request to query, correct, or remove personal information. The regional data flow regulations laid down by CP TPP, EPA and USMCA are adapted to the digital economy 
and business growth. They have a positive impact on the security of privacy and the promotion of the digital trade balance (Dai, 2020).

According to analysis, the legislation on cyberspace security and privacy protection should establish the critical role of facilitating the free flow of data. It classifies the personal information contained in the critical information infrastructure; establishes a cross-border transfer permit system. Sensitive data relating to personality orientation, health status, occupational characteristics, etc., shall be classified. A large number of non-sensitive data not included in this category shall be classified to allow the free flow of and non-localized storage. Because of the data monopoly issue, it is necessary to amend the Chinese Antimonopoly Law to incorporate new factors relevant to Internet competition to evaluate market dominance. However, the consideration of digital technology advancement and business model innovation should also be emphasized. To ensure data sharing and fair competition in the age of the digital economy, China's regulatory framework needs to speed up the implementation of the Personal Information Security Act (Sun, 2020).

\section{Conclusion}

Digital economic development requires breaking down digital trade barriers and realizing the free flow of data worldwide. However, the unrestricted data flow would bring significant secret threats to public security and personal privacy protection. The characteristics of digital economic development also make the digital market tend to monopolize, resulting in new problems of digital competition regulation. Currently, the design of rules or regulations on data flow, data localization, and source code opening in sizeable regional trade agreements or regulations represented by CPTPP, EPA, and USMCA and GDPR are forward-looking and progressive in promoting digital trade and privacy protection and is of positive significance in addressing new digital barriers in international trade. As a large country benefiting from the multilateral trading system, China's digital economy industry has already reached a certain development level. It is in China's interest to promote the reform of the multilateral service trade system. China should play a leading role in negotiating digital trade rules on issues such as data flow constraints and data localization criteria, encouraging negative inventory models for digital trade development within the multilateral framework, adhering to the primary position of enabling the free flow of data and classifying large volumes of non-sensitive personal data stored.

China should further improve relevant domestic laws and regulations and establish a legal system that guarantees the coordination of national cyberspace security, fair competition among enterprises, and the protection of personal information.

\section{References}

Agreement, J. F. T. (2019). Office of the United States trade representative. Retrieved from: https://downloads.regulations.gov/USTR-2018-0036-0136/content.pdf.

Bombińska, E. (2019). Servicification of manufacturing-the concept and consequences for international trade in services. Krakow International Studies, 16(2), 11-21.

Dai, 1. (2020). Data protection laws-one of the most important sources of competitive advantage in the context of international trade. Journal of Data Protection \& Privacy, 4(1), 72-80.

EU. (2019). European commission adopts adequacy decision on Japan, creating the world's largest area of safe data flows. Retrieved from https://ec.europa.eu/commission/presscorner/detail/en/IP_19_421

Filonova, O., Polyakova, E., Neverov, A., \& Mayboroda, T. (2020). Law support of the digital economy: Problems and prospects. In Ecological-Socio-Economic Systems: Models of Competition and Cooperation (ESES 2019) (pp. 460-465): Atlantis Press.

Gantz, D. A. (2018). The United States-Mexico-Canada agreement: Overview and analysis. Baker Institute Report, 12.

Gao, H. (2018). Digital or trade? The contrasting approaches of China and US to digital trade. Journal of International Economic Law, 21(2), 297-321.

Green, M. (2020). China's draft data security law: A practical review. Retrieved from: https://thediplomat.com/2020/09/chinas-draft-data-security-law-a-practical-review/.

Kahn, A., \& Wu, X. (2020). Impact of digital economy on intellectual property law. Journal of Politics and Law, $13(4), 117$. Available at: https://doi.org/10.5539/jpl.v13n4p117.

Kerber, W., \& Zolna, K. K. (2020). The German Facebook case: The law and economics of the relationship between competition and data protection law. Available at SSRN 3719098.

Khan, A., Jillani, M. A. H. S., Abd Elrhim, A. A., \& Soomro, N.-E. H. (2020). Plurilateral negotiation of WTO E-commerce in the context of digital economy: Recent issues and developments. Journal of Law and Political Sciences, 26(1), $28-54$.

Lee-Makiyama, H. (2014). Digital trade in the US and global economies. US International Trade Commission. Retrieved from: https://ecipe.org/wp-content/uploads/2014/12/USITC_speech.pdf.

Li, Y., Taeihagh, A., \& De Jong, M. (2018). The governance of risks in ridesharing: A revelatory case from Singapore. Energies, $11(5), 1277$. Available at: https://doi.org/10.3390/en1 1051277.

Liu, H. W. (2018). Data localization and digital trade barriers: ASEAN in Megaregionalism. ASEAN law in the new regional economic order: Global trends and shifting paradigms Pasha L. Hsieh \& Bryan Mercurio eds: Cambridge University Press.

Meltzer, J. P. (2015). The internet, cross-border data flows and international trade. Asia \& the Pacific Policy Studies, 2(1), 90-102. Available at: https://doi.org/10.1002/app5.60. 
Mitchell, A. D., \& Mishra, N. (2017). Data at the docks: Modernizing international trade law for the digital economy. Vanderbilt Journal of Entertainment and Technology Law, 20(4), 1073-1134.

Petri, P. A., Plummer, M. G., \& Zhai, F. (2012). The trans-pacific partnership and Asia-pacific integration: A quantitative assessment (Vol. 98): Peterson Institute.

Savelyev, A. (2016). Russia's new personal data localization regulations: A step forward or a self-imposed sanction? Computer Law \& Security Review, 32(1), 128-145. Available at: https://doi.org/10.1016/j.clsr.2015.12.003.

Shanxing, G. A. O., \& Weiqi, L. I. U. (2017). Regulation and reaction of cross-border data flows-A study of article 37, cybersecurity law. Journal of Xian Jiaobi University, 3, 85-91.

Sun, P. (2020). Security and privacy protection in cloud computing: Discussions and challenges. Journal of Network and Computer Applications, 160, 102642.

Trachtman, J. P. (2005). United States: Measures affecting the cross-border supply of betting and gambling services. $\mathrm{WT} / \mathrm{DS} 285 / \mathrm{AB} / \mathrm{R}$. American Journal of International Law, 99(4), 861-867. Available at: https://doi.org/10.2307/3396673.

Webb, P. (2003). A comparative analysis of data protection laws in Australia and Germany. The Journal of Information, Law and Technology $(2)$.

Wong, S. T., Hogg, W., Burge, F., Johnston, S., French, I., \& Blackman, S. (2018). Using the CollaboraKTion framework to report on primary care practice recruitment and data collection: Costs and successes in a cross-sectional practice-based survey in British Columbia, Ontario, and Nova Scotia, Canada. BMC Family Practice, 19(1), 1-13. Available at: https://doi.org/10.1186/s12875-018-0782-x.

$\mathrm{Wu}, \mathrm{X}$. (2009). Case note: China-measures affecting trading rights and distribution services for certain publications and audiovisual entertainment products (WT/DS363/AB/R). Chinese Journal of International Law, 9(2), 415-432. 